RESEARCH ARTICLE

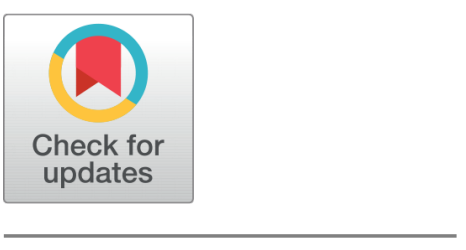

OPEN ACCESS

Received: 11.04.2021

Accepted: 29.04.2021

Published: 03.03.2021

Citation: Anushree SM, Nagesh P, Kulenur S (2021) The identification and evaluation of factors influencing quality management in selected higher education institutions. Indian Journal of Science and Technology 14(7): 628-635. https://d oi.org/10.17485/IJST/v14i7.223

* Corresponding author.

pnagesh1973@rediffmail.com, deanmgmt@jssstuni.in

Funding: None

Competing Interests: None

Copyright: (c) 2021 Anushree et al. This is an open access article distributed under the terms of the Creative Commons Attribution License, which permits unrestricted use, distribution, and reproduction in any medium, provided the original author and source are credited.

Published By Indian Society for Education and Environment (iSee)

ISSN

Print: 0974-6846

Electronic: 0974-5645

\section{The identification and evaluation of factors influencing quality management in selected higher education institutions}

\author{
S M Anushree ${ }^{1}$, P Nagesh $^{2 *}$, Sridevi Kulenur ${ }^{3}$ \\ 1 Research Scholar, Department of Management Studies, Sri Jayachamarajendra College of \\ Engineering JSS Science and Technology University, Mysore, 570 006, Karnataka, India \\ 2 Professor and Dean, Department of Management Studies, Sri Jayachamarajendra College \\ of Engineering JSS Science and Technology University, Mysore, 570 006, Karnataka, India \\ 3 Associate Professor, Department of Management Studies, Sri Jayachamarajendra College of \\ Engineering JSS Science and Technology University, Mysore, 570 006, Karnataka, India
}

\section{Abstract}

Objective: To identify critical factors that influences Service Quality (SQ) and also to know the inter-relationship between various factors that affect the Service Quality of the HEl. Method: The sample size was determined using a statistical method and 325 questionnaires were distributed, 316 valid responses were obtained from selected $\mathrm{HEI}$. The stratified random sampling procedure was adopted. The key factors that affect the SQ were determined using EFA and CFA. Further, relevant hypotheses were formulated to know the inter-relationship between factors that influences SQ of HEl. An attempt is made to develop the linear regression equation to estimate the Service Quality Score (SQC) of selected HEI based on factors confirmed by second-order CFA. Findings: The key factors that affect the SQ of the HEI were determined using EFA and CFA and such factors were labelled as Institutional assurance, Academic and support services, Empathy of staff, Responsiveness and Addon Provisions. Further, the estimation of Service Quality Score (SQC) using the above factors is obtained using a logical regression model and the service quality level of selected HEI is found to be 0.8285 i.e., $82.85 \%$. The study identifies the scope for continual improvement of factors that influence the SQ, more specifically the Academic and support services. The results of the present research are limited to the selected HEI and need to be validated for other courses and HEls. Novelty: The SERQUAL factors were considered but confirmation, revision and addition of factors are done using EFA followed by Second-order CFA. The results are more authenticated and help administer and to improve the service quality level of HEI.

Keywords: Higher education institution; service quality; service quality score; SERVQUAL 


\section{Introduction}

To understand, measure, establish and to improve service quality, it is absolutely necessary to measure service quality of high accuracy which in turn helps HEI to improve the Service Quality level (SQL). The quality of service plays a vital role to bring effectiveness in HEI to ensure student satisfaction. The HEI's organizational structure which is vertical in nature with 'silo-type' affects administration, workforce and creates ambiguity to see the managerial operations from a holistic perspective.

The research to know the importance of individual factors like administrative-academic-physical capacities and their effects on student's satisfaction is gaining its impotence in HEIs. The student satisfaction influenced by their positive perceptions about service quality will fascinate potential students by participating in positive communication with their contacts and friends and may arrive to HEI/University to enroll for subsequent courses.

Service quality is becoming a topmost priority of any service-providing organization but also it is noted that service quality research is relatively neglected in HEI. The service quality is not only indispensable but a factor to be considered to gain excellence in HEI. The Rapid progress in science, technology, commerce, growing demands for skilled professionals for Industries and commerce demands greater responsiveness and accountability, reorientation, redeployment of resources of HEI's. Thus, maintenance of standards and operational quality management in higher education turns out to be a herculean task. Operational benchmarks have been demarcated as a pivotal fulcrum for Quality management excellence in higher education institutions in the lieu of new education policy.

The objective of the present research is to identify critical factors that influence Service Quality (SQ) and also to know the inter-relationship between various factors that affect the Service Quality of the HEI. The outcome of the present research assists to comprehend the factors that are to be nurtured in order to strengthen the service quality by the administration of HEI's.

\section{Literature Review}

Mavondo, Felix \& Tsarenko, Yelena \& Gabbott, Mark. (2004) ${ }^{(1)}$ developed a conceptual model for assessing student satisfaction with universities and the likelihood of students recommending their institutions to other prospective students. Student satisfaction is conceptualised as a mediator between resources and capabilities and recommendation. The resources and capabilities that contribute to student satisfaction are identified as teaching, learning, technology, library, student services and student orientation. The resource needs of local and international students are compared. The data are analysed through path modelling, which results in a holistic perspective of the relationships. The findings suggest that more resources are required to satisfy local students than foreign students-that is, that local students perceive a larger pool of resources to be important for their satisfaction while foreign students appear to require a smaller pool. The implications of the study for university administrators are discussed and areas for future research are suggested.

Evans Ojiambo Onditi and Thaddeus Wafula Wechuli $(2017)^{(2)}$, states that service quality in higher is a multidimensional construct and there is no consensus among authors on the dimensions or the best model that should be used to evaluate service quality in institutions of higher learning. Further, mentioned various service quality construct in higher education such as competence of staff, the reputation of the institution, delivery styles by tutors and lecturers, reliability, tangibles, responsiveness, the sufficiency of resources, administrative services, and attitude support services. Also, authors recommend that a study be done to investigate the moderating effect of corporate reputation on the relationship between service quality and student satisfaction.

As summarized by Prentice, Garry, McLaughlin and Christopher $(2018)^{(3)}$, the traditional avenues of accreditation, module review and teaching evaluations are not the only ways to assess education service quality and related issues. In order to evaluate the education service provided by a private university in Ireland, this investigation utilized an extension of Cronin, Brady and Hult's (2000) model examining the effects of quality, value and customer satisfaction on customer intentions and behaviour. The model predicts that positive perceptions of quality, value and satisfaction in relation to the education service encounter will lead to positive word of mouth, and future intention to use the service again. Despite a slight majority stating that the service quality was above average, and the majority stating they were satisfied overall, only a minority indicated that they would use the service again.

Sreerama Raju and Udaya Bhaskar(2018) ${ }^{(4)}$, mentions that It is imperative for higher education institutions to understand the various dimensions of service quality and the need of continuous improvement in service quality for achieving sustainable development along with a competitive advantage. Further, the researchers noted that university education is a marketable service and students as the customers of the service. It is evident from the studies that the service quality dimensions vary across industries, county and culture.

As stated by Anup Kumar Das (2020) ${ }^{(5)}$, higher education in India is at the crossroads since the release of the National Education Policy 2020 by the Indian Ministry of Human Resource Development in July 2020 amidst the global COVID-19 
pandemic. The higher education experience mounting expectations of various stakeholders. The Rapid progress in science, technology, commerce, growing demands for skilled professionals for Industries and commerce demands greater responsiveness and accountability, reorientation, redeployment of resources of HEI's. Thus, maintenance of standards and operational quality management in higher education turns out to be a herculean task.

Chand and Khem. $(2020)^{(6)}$ have attempted has been made to determine factors of higher educational institution's service quality impact student satisfaction in Haryana. Data has been collected with the help of a designed questionnaire from various higher educational institutes of Haryana. Exploratory Factor analysis is applied for data analysis by IBM SPSS 20 to ascertain the determinants of higher educational institutions' service quality. The study identified eight factors alike Campus placement, administrative staff effectiveness, extra curriculum activities, physical support facility, teacher quality, supportive behaviour of staff, resource availability and problem-solving, and campus atmosphere which significantly influence student satisfaction in higher educational institutes. The result of this study has significance and higher education institutes should improve service quality offered by them to enhance student satisfaction.

Ruchi Rastogi and Ashutosh Priya $(2020)^{(7)}$, identified the challenges like the demand-supply gap, lack of quality research, the problem of infrastructure and basic facilities, shortage of faculty etc in higher education. Also suggested to improve the higher education system, to improve teaching pedagogy, build synergies between research and teaching, and facilitate the alliance of higher institutions among themselves, research centers and industries.

Varghese. $(2020)^{(8)}$, attentions that the NEP 2020 envisages the production of globally competitive and nationally grounded university graduates. New initiatives such as the GIAN and SPARC may promote internationalization at home by engaging foreign-trained professors, establishing collaborations with foreign universities, and revising the curriculum to make it globally relevant. In this context, providing service quality in HEIs is becoming a more predominant factor.

\section{The Research Gap}

With the extensive Literature review, it is noted that there is a strong need to know various factors that affect the service quality level of HEI and hence initiatives can be made to design and develop the methodology to quantify Service Quality Score (SQC) for selected HEIs. The suitable methods are to be devised to evaluate the critical factors and hence to measure the service quality and performance of HEIs. There is a need to establish the relationship between service quality and the performance of HEIs. The results of such research shall help the management to initiate suitable measures to enhance the performance and service quality to the next level and hence to provide the strategic directions for the betterment of the institution and to achieve operational excellence.

\section{Objectives of the Present Research}

The objective of the present research is to identify critical factors that influence Service Quality (SQ) and also to know the inter-relationship between various factors that affect the Service Quality of the HEI.

\section{The Research Design and Methodology}

Five-point Likert scale was used to elicit information from respondents (students) on their perception in relation to service quality. The sample size was determined using a statistical method and 325 questionnaires were distributed, 316 valid responses were obtained from selected HEI. The stratified random sampling procedure was adopted. A pilot survey comprising 48 items were used to elicit information from students about their level of satisfaction. The current study uses EFA followed by secondorder CFA to recognize the underlying factor structure determining the influence of service quality dimensions. The correlation analysis made on dimensions of service quality to know the relationship between variables selected. Model Fit Measures is developed for the fitness measure of EFA/CFA.

The attempt is made to understand factors that contributed more for various dimensions of Service quality. Further, Hypothesis Formulation and Testing with reference to Service Quality Factors is carried out to know the interrelationship between various factors to be considered for service quality assessment.

\section{The Framework and Data Analysis}

The EFA is to recognize the underlying factor structure determining the influence of service quality dimensions. The correlation analysis made on dimensions of service quality to know the relationship between variables selected. Model Fit Measures is developed for the fitness measure of EFA. The second-order Confirmatory Factor Analysis (CFA) is also carried out to confirm 
the factors that contribute the service quality. The Model fitness is confirmed using the Chi-square test (p-value is $<.001$ ) and hence it has been adopted in the present research.

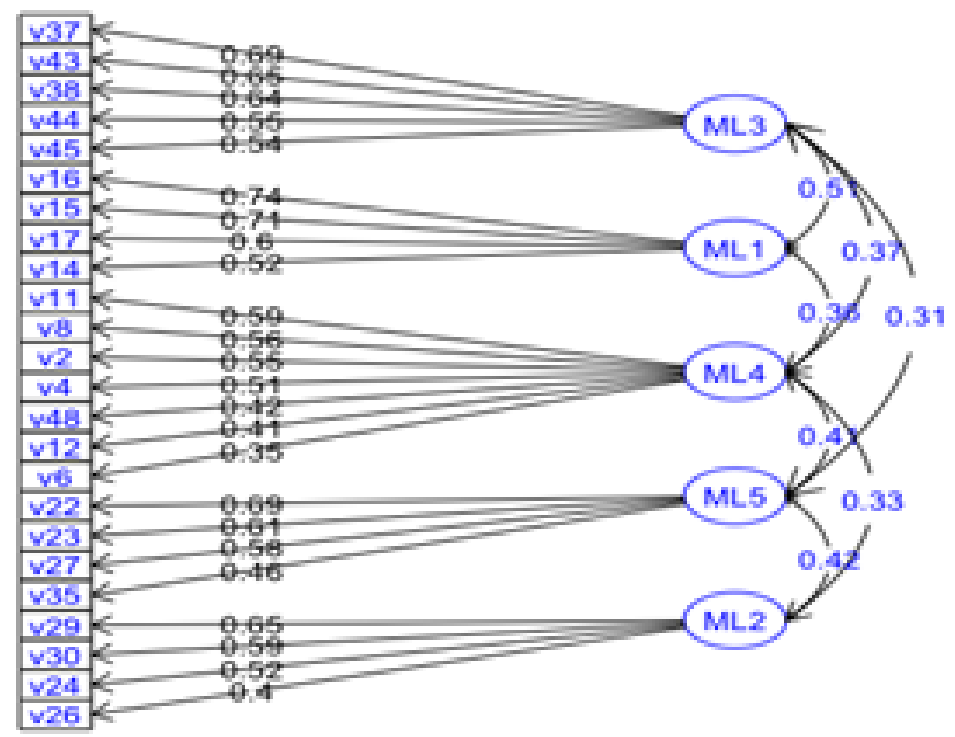

Fig 1. EFA of factors that affects the service quality of the HEIs

The factors that affect the Service Quality of the HEIs are labelled ML 1 to ML5 (Refer-1) as: FC1: Institutional assurance - IA, FC2: Academic and support services- A\&S, FC3: Empathy of staff- ES, FC4: Responsiveness-Res, and FC5: Add on Provisions -AP. Further, the efficiency of Cronbach's alpha of the above five factors were noted as $0.824,0.814,0.759,0.756$ and 0.703 respectively. The cut of a point is generally 0.5 (Nunnally,1978). Since all the reliability values lie between 0.703 and 0.824 , the construct of this questionnaire is reliable, thus the designed model has adequate measurement properties.

\subsection{Second order confirmatory factor analysis}

After $1^{\text {st }}$ order of CFA, $2^{\text {nd }}$ order of CFA is attempted to understand which factors contributed more for various dimensions of Service quality and all the five factors are maintained without elimination of items. The Figure 2, depicts the Second order of Confirmatory analysis.

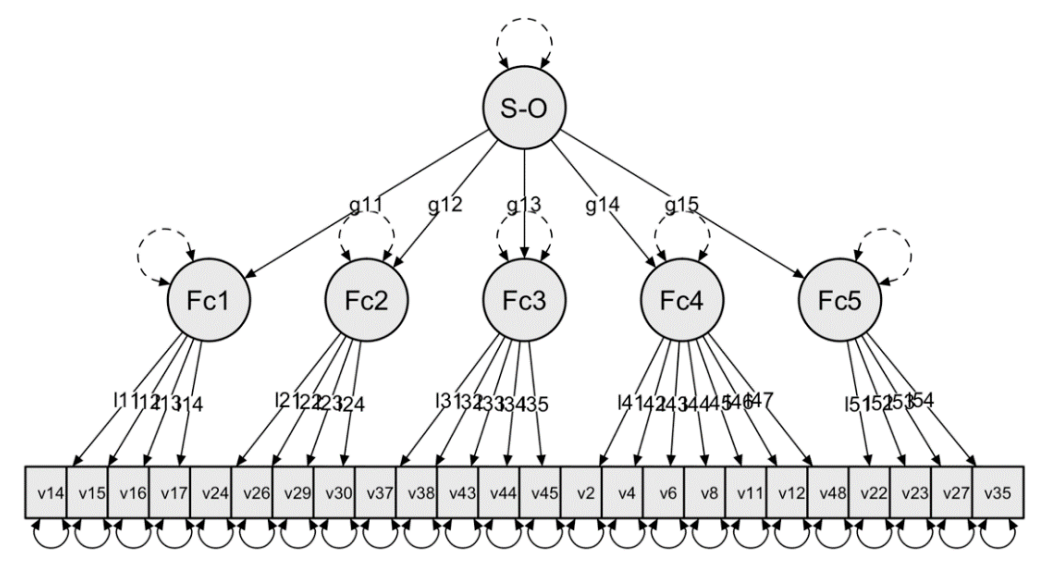

Fig 2. Model plot of second order confirmatory factor analysis 
Table 1. Chi-square test

\begin{tabular}{llll}
\hline Model & $X^{2}$ & df & P \\
\hline Baseline model & 2552.3 & 276 & \\
Factor model & 483.5 & 247 & $<.001$ \\
\hline
\end{tabular}

\subsection{The framework for hypothesis formulation and testing}

The framework is developed for hypothesis formulation and testing and also to know inter- relationship between the factors that influence the Service Quality of the HEIs (Figure 3).

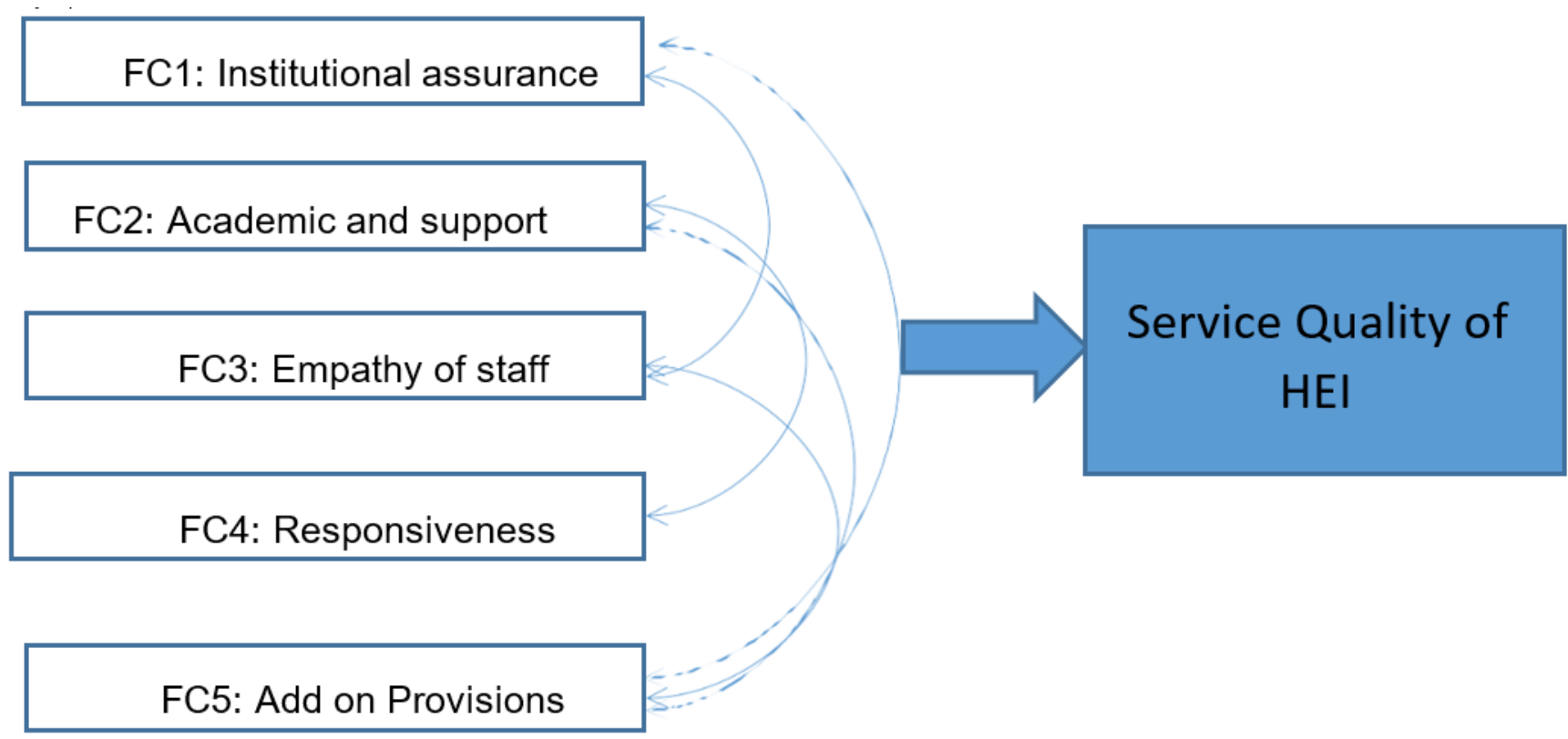

Fig 3. Frame work for hypothesis testing with reference to SQ of HEI

Table 2. Hypothesis testing results with reference to SQ factors of HEI

\begin{tabular}{|c|c|c|c|c|}
\hline Null Hypothesis (H0) & t- Value & Sig. & Confidence level & Decision \\
\hline $\begin{array}{l}\text { H1: There is no significant mean differences prevailing towards } \\
\text { the perception of relationship between Institutional assurance } \\
\text { (FC1) and Service Quality (SQ). }\end{array}$ & -7.231 & .000 & $95 \%$ & Sig \\
\hline $\begin{array}{l}\text { H2: There is no significant mean differences prevailing towards } \\
\text { the perception of relationship between Academic and support } \\
\text { services (FC2) and Service Quality (SQ). }\end{array}$ & 2.597 & .010 & $95 \%$ & Sig \\
\hline $\begin{array}{l}\text { H3: H1: There is no significant mean differences prevailing } \\
\text { towards the perception of relationship between Empathy of staff } \\
\text { (FC3) and Service Quality (SQ). }\end{array}$ & -9.179 & .000 & $95 \%$ & Sig \\
\hline $\begin{array}{l}\text { H4: H1: There is no significant mean differences prevailing } \\
\text { towards the perception of relationship between Responsiveness } \\
\text { (FC4) and Service Quality (SQ). }\end{array}$ & 2.597 & .010 & $95 \%$ & Sig \\
\hline $\begin{array}{l}\text { H5: H1: There is no significant mean differences prevailing } \\
\text { towards the perception of relationship between Add on Provisions } \\
\text { (FC5) and Service Quality (SQ). }\end{array}$ & 12.781 & .000 & $95 \%$ & Sig \\
\hline $\begin{array}{l}\text { H6: There is no significant mean differences prevailing towards } \\
\text { the perception of relationship between Institutional assurance } \\
\text { (FC1) and Academic and support services (FC2). }\end{array}$ & 5.736 & .000 & $95 \%$ & Sig \\
\hline
\end{tabular}




\section{Table 2 continued}

\begin{tabular}{|c|c|c|c|c|}
\hline $\begin{array}{l}\text { H7: There is no significant mean differences prevailing towards } \\
\text { the perception of relationship between Institutional assurance } \\
\text { (FC1) and Empathy of staff (FC3). }\end{array}$ & -.760 & .448 & $95 \%$ & Non-Sig \\
\hline $\begin{array}{l}\text { H8: There is no significant mean differences prevailing towards } \\
\text { the perception of relationship between Institutional assurance } \\
\text { (FC1) and Responsiveness (FC4). }\end{array}$ & 5.736 & .000 & $95 \%$ & Sig \\
\hline $\begin{array}{l}\text { H9: There is no significant mean differences prevailing towards } \\
\text { the perception of relationship between Institutional assurance } \\
\text { (FC1) and Add on Provisions (FC5). }\end{array}$ & 11.920 & .000 & $95 \%$ & Sig \\
\hline $\begin{array}{l}\text { H10: There is no significant mean differences prevailing towards } \\
\text { the perception of relationship between Academic and support } \\
\text { services (FC2) and Empathy of staff (FC3). }\end{array}$ & -6.592 & .000 & $95 \%$ & Sig \\
\hline $\begin{array}{l}\text { H11: There is no significant mean differences prevailing towards } \\
\text { the perception of relationship between Academic and support } \\
\text { services (FC2) and Add on Provisions (FC5). }\end{array}$ & 7.478 & .000 & $95 \%$ & Sig \\
\hline $\begin{array}{l}\text { H12: There is no significant mean differences prevailing towards } \\
\text { the perception of relationship between Empathy of staff(FC3) and } \\
\text { Responsiveness (FC4). }\end{array}$ & 6.592 & .000 & $95 \%$ & Sig \\
\hline $\begin{array}{l}\text { H13: There is no significant mean differences prevailing towards } \\
\text { the perception of relationship between Empathy of staff (FC3) and } \\
\text { Add on Provisions (FC5). }\end{array}$ & 13.000 & .000 & $95 \%$ & Sig \\
\hline $\begin{array}{l}\text { H14: There is no significant mean differences prevailing towards } \\
\text { the perception of relationship between Responsiveness (FC4) and } \\
\text { Add on Provisions (FC5). }\end{array}$ & -7.478 & .000 & $95 \%$ & Sig \\
\hline
\end{tabular}

\section{Results of hypothesis testing with reference to factors that influence SQ of HEI}

1. H1: There is no significant mean differences prevailing towards the perception of the relationship between Institutional assurance (FC1) and Service Quality (SQ). The study fetches that the t- value is -7.231 and P value is 0.000 . As the significant value is less than 0.05 , the mean differences prevailing about the perception of this factor is significant at $5 \%$ level.

2. H2: There is no significant mean differences prevailing towards the perception of relationship between Academic and support services (FC2) and Service Quality (SQ). The study fetches that the t-value is 2.597 and $\mathrm{P}$ value is .010. As the significant value is less than 0.05 , the mean differences prevailing about the perception of this factor is significant at $5 \%$ level.

3. H3: There is no significant mean differences prevailing towards the perception of the relationship between Empathy of staff (FC3) and Service Quality (SQ). The study fetches that the t- value is -9.179 and P value is 0.000 . As the significant value is less than 0.05 , the mean differences prevailing about the perception of this factor is significant at $5 \%$ level.

4. H4: There is no significant mean differences prevailing towards the perception of the relationship between Responsiveness (FC4) and Service Quality (SQ). The study fetches that the t- value is 2.597 and P value is .010. As the significant value is less than 0.05 , the mean differences prevailing about the perception of this factor is significant at $5 \%$ level.

5. H5: There is no significant mean differences prevailing towards the perception of the relationship between Add on Provisions (FC5) and Service Quality (SQ). The study fetches that the t- value is 12.781 and P value is 0.000 . As the significant value is less than 0.05 , the mean differences prevailing about the perception of this factor is significant at $5 \%$ level.

6. H6: There is no significant mean differences prevailing towards the perception of the relationship between Institutional assurance (FC1) and Academic and support services (FC2). The study fetches that the t-value is 5.736 and $\mathrm{P}$ value is 0.000 . As the significant value is less than 0.05 , the mean differences prevailing about the perception of this factor is significant at $5 \%$ level.

7. H7: There is no significant mean differences prevailing towards the perception of relationship between Institutional assurance (FC1) and Empathy of staff (FC3). The study fetches that the t- value is -.760 and P value is .448. As the significant value is less than 0.05 , the mean differences prevailing about the perception of this factor is Non-significant at $5 \%$ level. 
8. H8: There is no significant mean differences prevailing towards the perception of relationship between Institutional assurance (FC1) and Responsiveness (FC4). The study fetches that the t- value is 5.736 and $\mathrm{P}$ value is 0.000 . As the significant value is less than 0.05 , the mean differences prevailing about the perception of this factor is significant at $5 \%$ level.

9. H9: There is no significant mean differences prevailing towards the perception of relationship between Institutional assurance (FC1) and Add on Provisions (FC5). The study fetches that the t- value is 8.55 and $\mathrm{P}$ value is 0.000 . As the significant value is less than 0.05 , the mean differences prevailing about the perception of this factor is significant at $5 \%$ level.

10. H10: There is no significant mean differences prevailing towards the perception of relationship between Academic and support services (FC2) and Empathy of staff (FC3). The study fetches that the t- value is -6.592 and P value is 0.000 . As the significant value is less than 0.05 , the mean differences prevailing about the perception of this factor is significant at $5 \%$ level.

11. H11: There is no significant mean differences prevailing towards the perception of relationship between Academic and support services (FC2) and Add on Provisions (FC5). The study fetches that the t- value is 7.478 and P value is 0.000 . As the significant value is less than 0.05 , the mean differences prevailing about the perception of this factor is significant at $5 \%$ level.

12. H12: There is no significant mean differences prevailing towards the perception of relationship between Empathy of staff (FC3) and Responsiveness (FC4). The study fetches that the t- value is 6.592 and P value is 0.000 . As the significant value is less than 0.05 , the mean differences prevailing about the perception of this factor is significant at $5 \%$ level.

13. H13: There is no significant mean differences prevailing towards the perception of relationship between Empathy of staff (FC3) and Add on Provisions (FC5). The study fetches that the t- value is 13.00 and $\mathrm{P}$ value is 0.000 . As the significant value is less than 0.05 , the mean differences prevailing about the perception of this factor is significant at $5 \%$ level.

14. H14: There is no significant mean differences prevailing towards the perception of relationship between Responsiveness (FC4) and Add on Provisions (FC5). The study fetches that the t- value is -7.478 and P value is 0.000 . As the significant value is less than 0.05 , the mean differences prevailing about the perception of this factor is significant at $5 \%$ level.

\section{Assessment of service quality scores for HEls}

\subsection{Predictive model: Regression analysis}

An attempt is made to develop the linear regression equation to estimate the Service Quality Score (SQC) of selected HEI based on factors confirmed by second-order CFA. The findings and analysis are mentioned below section.

IV: Key factors that affect the SQ of the HEIs

X1 - FC1: Institutional Assurance (IA) X2 - FC2: Academic and support X4- FC4: Responsiveness (RS) X5- FC5: Add on Provisions services (AS) X3- FC3: Empathy of Staff (ES) (AOP) e- Error term.

$$
Y=a+\beta 1 * X 1+\beta 2 * X 2+\beta 3 * X 3+\beta 4 * X 4+\beta 5 * X 5+e i
$$

Thus,by substituting coefficients of dependent variables, regression equation for the estimation of Service Quality Score of selected HEI may be obtained as follows.

$$
Y=.096+.237^{*} \times 1+.741^{*} \times 2+.277^{*} \times 3-.507^{*} \times 4+.231^{*} \times 5
$$

From the equation mentioned above, it may be understood that, SQ Score of the HEI as outcome variable and rest of the variables are predictors, the expected relation between DV and IV is positive.

By replacing variables with its mean values as per Descriptive Statistics from the Table in the above equation, the Service Quality Score of selected HEI is obtained as follows.

$$
Y=.096+.237^{*} 4.31+.741^{*} 4.07+.277^{*} 4.34-.507^{*} 4.07+.231^{*} 3.77
$$

Therefore, the Service Quality Score (SQS) of selected HEI $(Y)=4.1429$. The grand mean score of all factors which influences the SQ of HEI is 4.1120. Thus, the overall Service Quality Score of selected HEI $(\mathrm{Y})=4.1429$, which may be understood as 4.1429 out of 5 (as the maximum rating of 5 point) lead to SQC of 0.8285 i.e., $82.85 \%$. 


\section{Results and Conclusions}

In Factor 1, item v14, v15, v16 and v17 are loaded, factors are named as Institutional Assurance, Factor 2, item v24, v26, v29, and v30 are loaded, factors are named as Academic and support services, In Factor 3, item v37, v38, v4 , v43, v44 and v45 are loaded, factors are named as Empathy of staff, In Factor 4, item v2, v4, v6, v8, v11 and v12 are loaded, factors are named as Responsiveness and Factor 5, item v22, v23, v27 and v35 are loaded and factors are named as Responsiveness v15 is highly loaded, in ML1, item v38 is high, in ML4, item29, factors are named as Add on Provisions. With reference to hypothesis testing, there were 14 hypotheses were formulated as presented in Table 2 . After $1^{\text {st }}$ order of CFA, $2^{\text {nd }}$ order of CFA is attempted, in order to understand which factors contributed more for various dimensions of Service quality, all the five factors are maintained, and no items are eliminated.

The results show that except that no significant mean differences prevailing towards the perception of the relationship between Institutional assurance (FC1) and Empathy of staff (FC3), remaining are factors possessed the mean differences prevailing about the perception at significant at 5\% level. The results also confirmed the inter-relationship between critical factors designated under study.

The linear regression equation has been developed to estimate the Service QualityScore (SQC) of selected HEI based on factors confirmed by second-order CFA. Thus, by substituting coefficients of dependent variables, regression equation for the estimation of Service Quality Score of selected HEI may be obtained.

$$
Y=.096+.237^{*} \times 1+.741^{*} \times 2+.277^{*} \times 3-.507^{*} \times 4+.231^{*} \times 5
$$

From the equation mentioned above, it may be understood that SQ Score of the HEI as outcome variable and the rest of the variables are predictors, the expected relation between DV and IV is positive. By replacing variables with their mean values as per the Descriptive Statistics from the Table in the above equation, the Service Quality Score of selected HEI is obtained as follows. Thus, the overall Service Quality Score of selected HEI (Y) $=4.1429$, which may be understood as 4.1429 out of 5 (as the maximum rating of 5 points) lead to SQC of 0.8285 i.e., $82.85 \%$.

\section{References}

1) Mavondo F, Tsarenko Y, Gabbott M. International and Local Student Satisfaction: Resources and Capabilities Perspective. $2004 . \quad$ Available from: https://doi.org/10.1300/J050v14n01_03.

2) Onditi O, Wechuli TW. Service Quality and Student Satisfaction in Higher Education Institutions: A Review of Literature. Evans International Journal of Scientific and Research Publications. 2017;7(7). Available from: http://www.ijsrp.org/research-paper-0717/ijsrp-p6737.pdf.

3) Prentice G, Brady J, McLaughlin C. Education Service Quality, Value and Satisfaction on Student Customer Intentions and Behaviour. DBS Business Review. 2018;2. Available from: https://dx.doi.org/10.22375/dbr.v2i0.27.

4) Raju MS, Bhaskar NU. Service Quality in Higher Education -A Critical Review. In: and others, editor. International conference of Applied Science, Technology and Management. 2018.

5) Das AK. Understanding the Changing Perspectives of Higher Education in India. Journal of Scientometric Research. 2020;9(2):226-228. Available from: https://dx.doi.org/10.5530/jscires.9.2.28.

6) Chand, Khem. (2020), Study Factors of Higher Educational Institution's Service Quality on Student Satisfaction in Haryana, Restaurant Business. 118. 1451-1462. ISSN: 0097-8043 Vol-118-Issue-11-November-2019. .

7) Rastogi R, Priya A. Recent Trends in Indian Higher Education System. International Journal of Advanced Science and Technology. 2020;29(8s):2216-2222. Available from: http://sersc.org/journals/index.php/IJAST/article/view/14462.

8) Varghese NV. Internationalisation and Cross-Border Mobility in Indian Higher Education. International Journal of African Higher Education. 2020;7(2). Available from: https://doi.org/10.6017/ijahe.v7i2.12901. 